\title{
Study on Tractor Semi-Trailer Roll Stability Control
}

\author{
Shuwen Zhou ${ }^{*}, 1$ and Siqi Zhang ${ }^{2}$ \\ ${ }^{I}$ School of Mechanical Engineering and Automation, Northeastern University, Shenyang 110004, China \\ ${ }^{2}$ Traffic \& Mechanical Engineering School, Shenyang Jianzhu University, Shenyang 110168, China
}

\begin{abstract}
The rollover accidents in the tractor semi-trailer are often fatal and many factors could cause the tractor semitrailer rollover. In this paper, a rollover prevention control method was proposed based on real-time calculation of rollover index. The vehicle Center of Gravity (CG) height from the ground is an important parameter in the rollover index and it is estimated through lateral acceleration sensor and suspension deflection sensors. Comparing the rollover index with the preset threshold, the differential braking will be applied to corresponding wheels once the trigger conditions are met. A roll stability control simulation was performed on the dynamic model based on virtual prototyping. The results show that the rollover prevention control proposed in this paper can stabilize the tractor semi-trailer and prevent from rollover on high speed curve driving.
\end{abstract}

Keywords: Curve driving, differential braking, roll stability, tractor semi-trailer, Center of Gravity, Rollover index.

\section{INTRODUCTION}

Lateral instability phenomena will likely occur in tractor semi-trailers on high speed obstacle avoidance under emergency or during high speed curve driving. Yaw instability usually occurs on low adhesion surface and rollover occurs on a high adhesion surface [1-3].

Although tractor semi-trailer rollover accidents are not frequent occurrences, fatalities associated with rollovers are high. In addition, it is not unusual for the economic losses of the payload and other associated insurance costs to be significant to the transporter [4].

In general, as a transport vehicle, the tractor semi-trailer is subject to wide variation in loading. The weight and distribution of the cargo load both influence the Center of Gravity (CG) height of the truck.

Therefore, factors affecting tractor semi-trailer rollover usually include vehicle types, vehicle stiffness, vehicle speed, steering angle, vehicle payload, the CG of the payload, tires, suspensions and the roadway surfaces/tire adhesion coefficient. Fig. (1) shows a tractor semi-trailer rollover accident due to the vehicle overturned while entering the highway.

It has been investigated that the CG height largely affects the roll dynamics, including roll time and maximum roll angle [5].

The main task in the design of roll stability control system is to calculate the rollover index, which indicates the likelihood of the vehicle to roll over and it is used to trigger differential braking to prevent rollover. In order to ensure that rollovers can be prevented in time, accurate rollover

*Address correspondence to this author at the School of Mechanical Engineering and Automation, Northeastern University, Shenyang 110004, China; Tel: +8624-83691095; E-mail: shwzhou@mail.neu.edu.cn index is necessary. The calculation of rollover index will include the CG height.

However, there is no accurate way to measure the height of CG nowadays. There are several estimation methods to obtain the vehicle CG height in real-time.

The vehicle CG height can be estimated in real-time based on an accurate observation of the vehicle roll angle, or utilizing an extended Kalman filter [6,7].

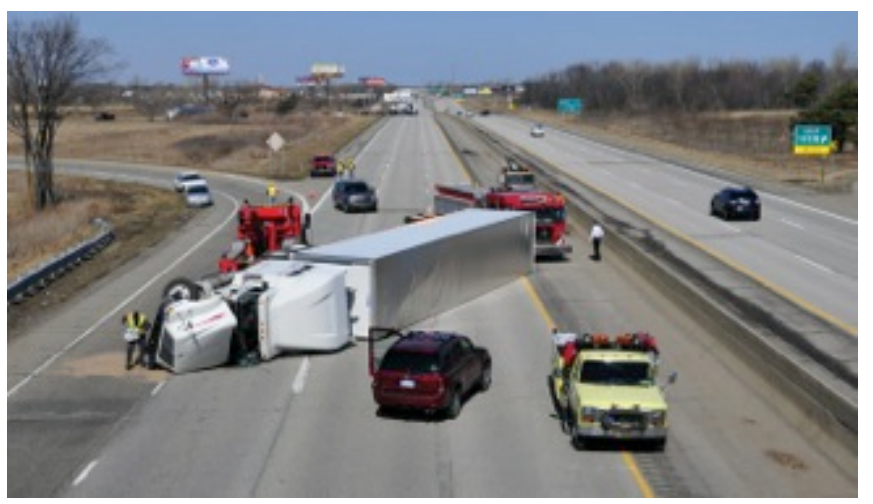

Fig. (1). Tractor semi-trailer rollover accident.

In this paper, the CG height is estimated based on the suspension deflection. The estimated CG height of the vehicle is used to calculate the rollover index and adjust various calibrated rollover detection thresholds.

Based on the calculation results of rollover index, a rollover prevention control will be performed, the maximum braking pressure is applied on the outer wheels. Certainly, braking pressure on the outer wheels is adjusted simultaneously by the antilock brake system so that these outer wheels cannot be locked.

A virtual prototyping model of tractor semi-trailer was used to simulate vehicle rollover detection and prevention 
during high speed bend driving situations. The simulation results show that the rollover detection and prevention methods can improve the tractor semi-trailer lateral stability during high speed bend driving situations.

\section{ROLLOVER INDEX}

The basic measure of roll stability is the static rollover threshold, expressed as lateral acceleration in gravitational units (g). Most passenger cars have rollover thresholds greater than $1 \mathrm{~g}$, while that of light trucks, vans, and SUVs range from 0.8 to $1.2 \mathrm{~g}$. However, the rollover threshold of a loaded heavy truck often lies well below $0.5 \mathrm{~g}$.

The typical U.S. five-axle tractor-van semitrailer combination, when loaded to legal gross weight, has a rollover threshold as high as $0.5 \mathrm{~g}$ with an optimal highdensity, low CG load. The roll-over threshold drops to as low as $0.25 \mathrm{~g}$ with a maximum load that completely fills the volume of the trailer [8].

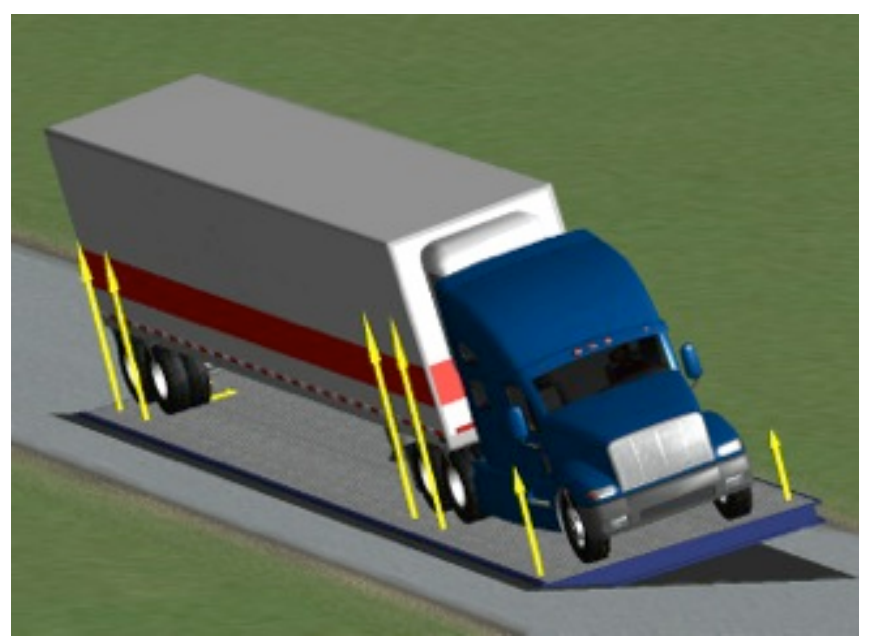

Fig. (2). Tilt table testing.

The tilt table test provides a highly resolute method of determining rollover threshold and a convenient means for examining the mechanisms by which this limit is determined. The methodology is a physical simulation of the roll-plane experience of a vehicle during quasi steady-state turning. In this experimental method, the vehicle is placed on a tilt table and is very gradually tilted in roll, as shown in Fig. (2). The component of gravitational forces parallel to the table surface provides a simulation of the centrifugal forces experienced by a vehicle in turning maneuvers. The progressive application of these forces achieved by slowly tilting the table serves to simulate the effects of quasistatically increasing lateral acceleration in progressively more severe and steady turnings. The tilting process continues until the vehicle reaches the point of roll instability and "rolls over".

A rollover index, which indicates an impending rollover, can be defined with the real-time difference in vertical tire loads between the left and right sides of the vehicle. Fig. (3) shows a schematic of a vehicle with a sprung mass that undergoes roll motion. The difference between the normal reaction force of the road against the tire $F_{z l}$ and $F_{z r}$ caused by the roll motion of the vehicle is used to define rollover index R (load transfer rate) as:
$R_{i n}=\frac{F_{z r}-F_{z l}}{F_{z r}+F_{z l}}$

These loads are monitored to detect any lateral load transfer. Detected lateral load transfer is divided by the overall load to produce a load transfer ratio $R_{i n}$. $R_{i n}$ is related to vehicle roll stability and can be obtained with loads measured for a single axle or for any combination of multiple axles.

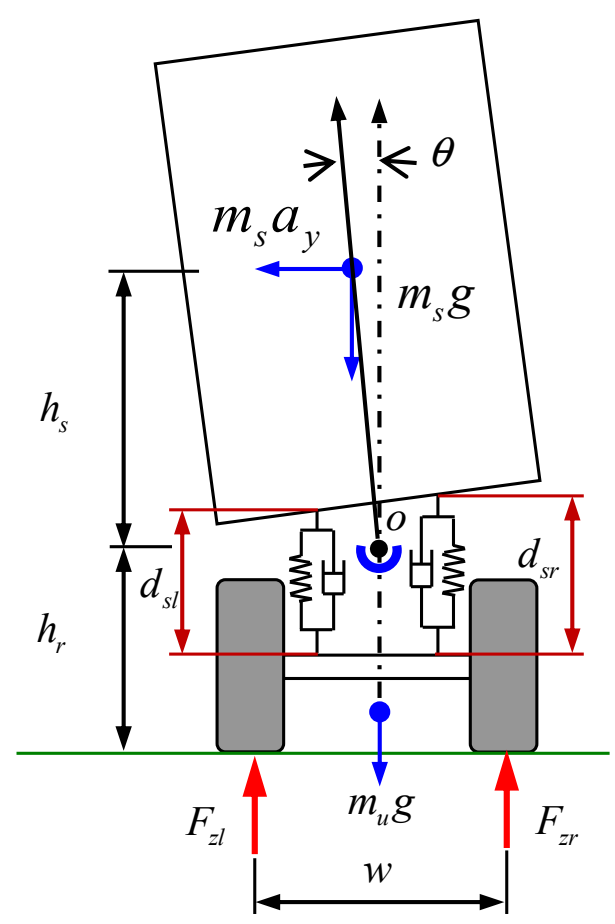

Fig. (3). Semi-trailer roll model.

When the loads on each side of the vehicle are equal, then $R_{i n}=0$ and there is no predicted rollover danger. At incipient rollover, the load on one side is completely transferred to the other side and then it is $R_{i n}= \pm 1$, which indicates one side wheel lifts off the road. Therefore, if $R_{i n}$ is close to \pm 1 , the rollover risk will increase.

According to the force analysis on the semi-trailer, the rollover index can be further organized:

$$
\begin{aligned}
R_{i n} & =\frac{F_{z r}-F_{z l}}{F_{z r}+F_{z l}} \\
& =\frac{2 m_{s}}{\left(m_{s}+m_{u}\right) w_{s}}\left(\left(h_{r}+h_{s} \cos \theta\right) \frac{a_{y}}{g}+h_{s} \sin \theta\right)
\end{aligned}
$$

where $m_{s}$ is the sprung mass, $m_{u}$ is the unsprung mass, $\theta$ is the sprung mass roll angle, $h_{r}$ is the height of roll center, $h_{s}$ is the sprung mass CG height, $a_{y}$ is the lateral acceleration, $d_{s l}$ and $d_{s r}$ are the suspension deflection, $w$ is the track width. 
Since $m_{u} \ll m_{s}$ and the sprung mass roll angle is small, so equation (2) can be written as:

$$
R_{i n} \approx \frac{2\left(h_{r}+h_{s}\right)}{w_{s}} \frac{a_{y}}{g}
$$

The rollover susceptibility of a transport vehicle varies dramatically with the placement, distribution and weight of its cargo load because these factors alter the vehicle's CG. For example, a semi-trailer with a full load of cotton will have a higher CG than a flatbed trailer loaded with a single slab of pig iron. So the sprung mass CG height $h_{s}$ varies greatly, but the height of roll center $h_{r}$ changes little. $h_{r}$ can be amended after the total mass is estimated. The lateral acceleration $a_{y}$ can be measured using lateral acceleration sensor.

Therefore, in order to accurately calculate the rollover index, it needs to estimate the sprung mass CG height.

According to vehicle roll dynamics, the following equation can be obtained:

$$
\begin{aligned}
\left(I_{x^{\prime} x^{\prime}}+m_{s} h_{s}^{2}\right) \ddot{\theta} & =m_{s} a_{y} h_{s} \cos \theta+m_{s} g h_{s} \sin \theta- \\
& \frac{1}{2} k_{s} l_{s}^{2} \cos \theta \sin \theta-\frac{1}{2} c_{s} l_{s}^{2}\left(\cos ^{2} \theta\right) \dot{\theta}
\end{aligned}
$$

where, $k_{s}$ is suspension stiffness, $l_{s}$ is the distance between left suspension and right one, $c_{s}$ is the suspension damping.

Since roll angle in the steady-state cornering is a constant, equation (4) can be rewritten as:

$h_{s}=\frac{-\frac{1}{2} k_{s} l_{s}^{2} \cos \theta \sin \theta}{m_{s} a_{y} \cos \theta+m_{s} g \sin \theta}$

Where the sprung mass roll angle $\theta$ can be estimated with state observer or be calculated using suspension deflection sensors.

So the rollover index can be obtained with equation (2) and equation (5).

\section{ROLLOVER PREVENTION}

The electronic control unit in the tractor semi-trailer constantly detects the vehicle speed, lateral acceleration and suspension deflection through sensors, and the rollover index is calculated in real time. Once the calculation value exceeds the preset threshold, the differential braking will be applied to corresponding wheels.

The traditional method is to apply braking pressure on the outer wheels of the tractor, and the braking pressure is also applied to' wheels on both sides of the of the semitrailer, as shown in Fig. (4).

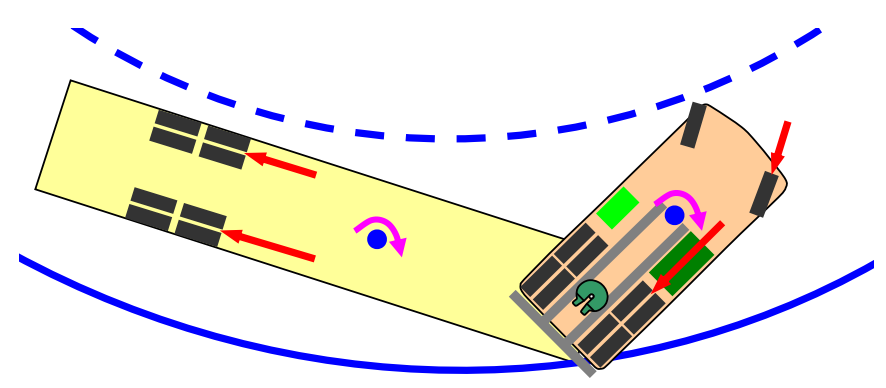

Fig. (4). Traditional rollover prevention control.

Due to the load transfer effect, the outer wheels will experience increased normal force than the inner wheels, which means the outer wheels can afford more brake force than the inner wheels do. This unequal force will deteriorate the rollover situation of the tractor.

In this paper, the rollover prevention control system will use low-election principle, that is to say, the outer wheels of semi-trailer will be applied the same brake pressure as the inner wheel, as shown in Fig. (5). The new method will be able to prevent rollover more efficiently.

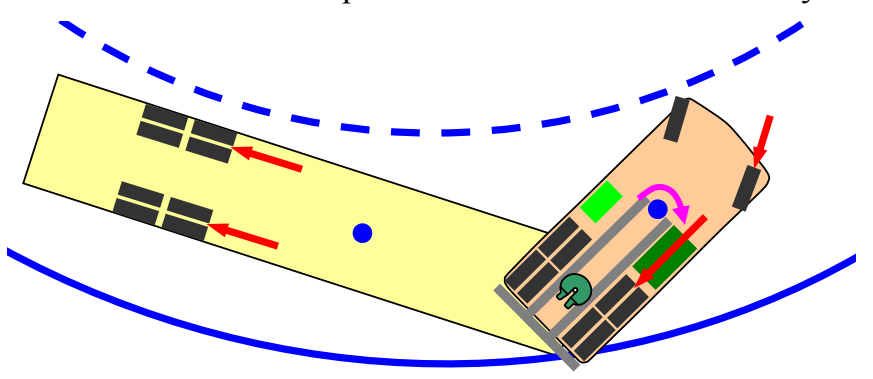

Fig. (5). New rollover prevention control.

\section{VIRTUAL PROTOTYPING SIMULATION}

In order to test the performance of this rollover prevention control system, a dynamic analysis was performed with Adams/Car and Simulink [9]. The full vehicle was assembled in ADAMS/CAR, as shown in Fig. (6).

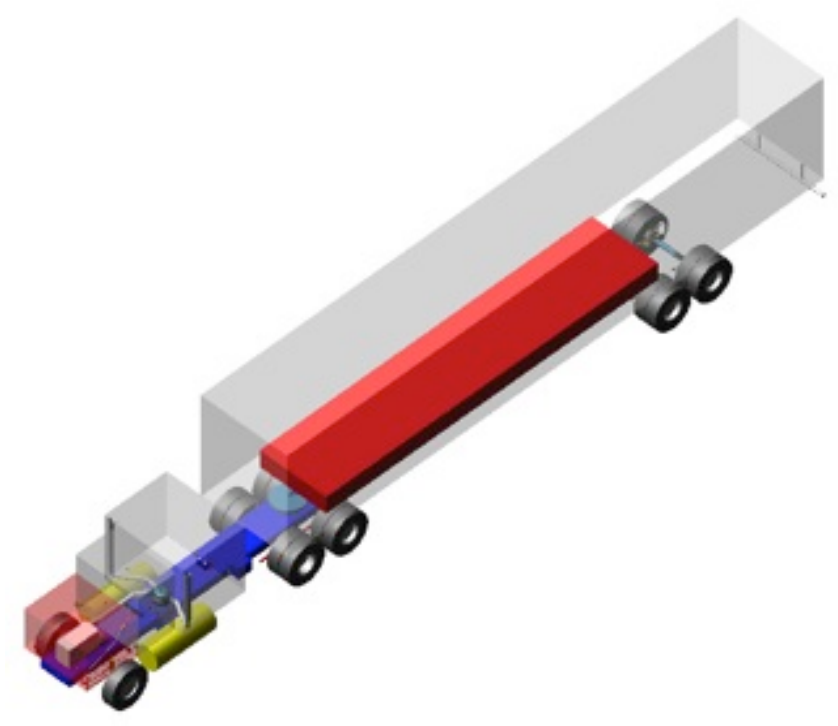

Fig. (6). Virtual prototyping model. 
The rollover prevention control system for tractor semi-trailer is designed in Simulink. There are 22 input variables from virtual prototyping model (output variables in ADAMS). They are 10 wheel speeds, 10 suspension deflection displacements, one vehicle speed and one braking pressure. And there are 10 output variables, i.e. 10 wheels' braking pressure in the control system, which are also the input variables in ADAMS.

Test conditions for the dynamic analysis is a step angle input on the steering wheel, as shown in Fig. (7).

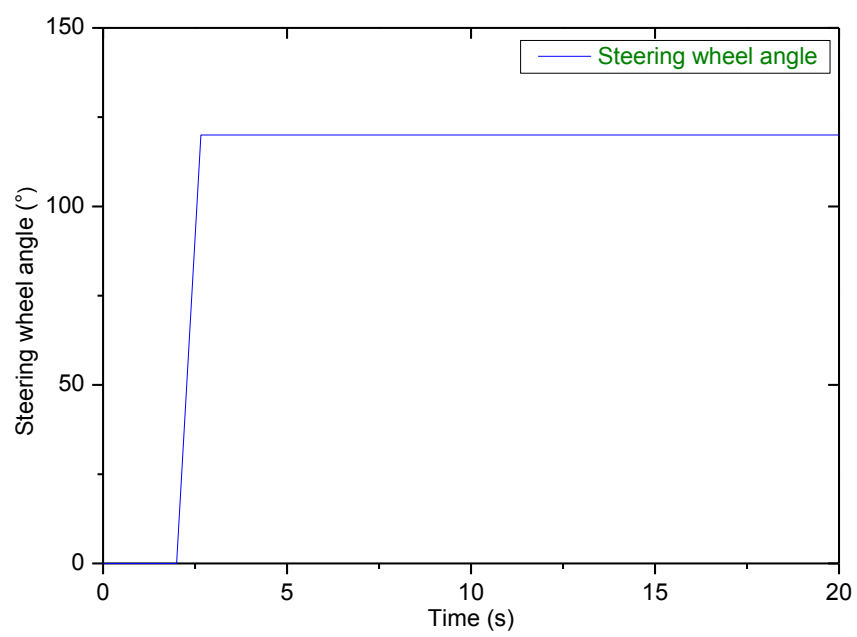

Fig. (7). Steering wheel angle.

The test is performed in which the tractor semi-trailer is traveling at $90 \mathrm{~km} / \mathrm{h}$. The road adhesion coefficient is 0.85 .

\section{SIMULATION RESULTS}

Since the tractor semi-trailer has a high CG, and travels at high speed on the high adhesion coefficient road, a not very large steering wheel angle input will lead to the vehicle rollover. Fig. (8) is the roll angle of the tractor semi-trailer without rollover prevention control. It can be seen from Fig. (8), the tractor semi-trailer has rollovered.

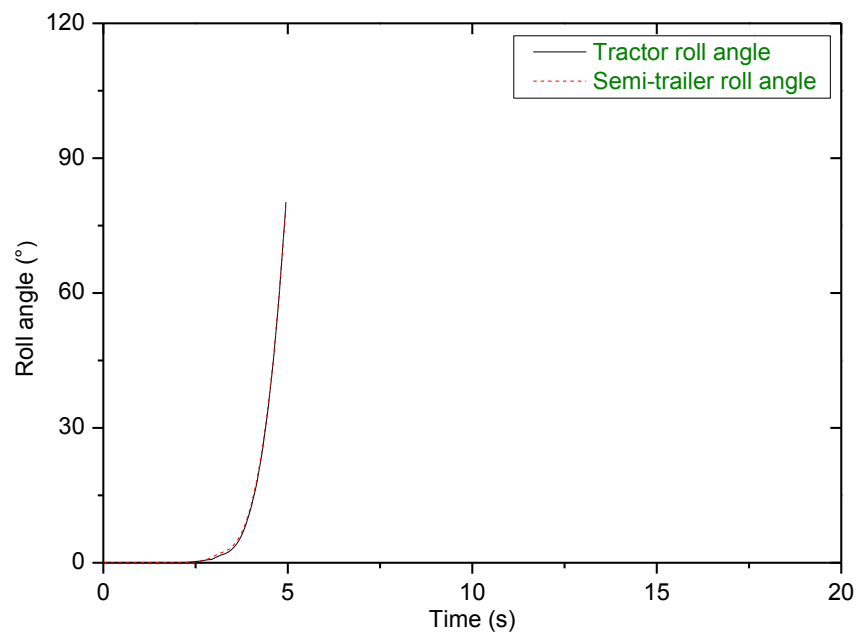

Fig. (8). Roll angle without rollover prevention.

With the rollover prevention control proposed in this paper, the control system constantly calculates the rollover index and compares the real-time index with the preset threshold.

Once the trigger conditions are met, an appropriate braking pressure will be applied on the outer wheels of the tractor and the same braking pressure on the' wheels of both sides of the semi-trailer

The simulation results of the rollover prevention control are shown in Figs. (9-11).

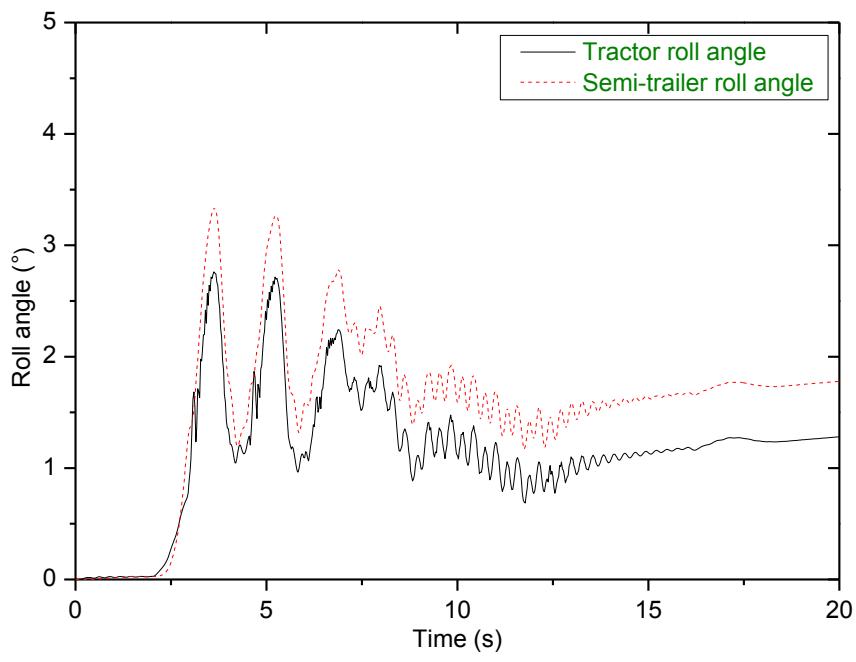

Fig. (9). Roll angle with rollover prevention.

Fig. (9) is the roll angle of the tractor semi-trailer with rollover prevention control. As can be seen from the figure, with the rollover prevention control, the roll angles of the vehicle are maintained at a lower level.

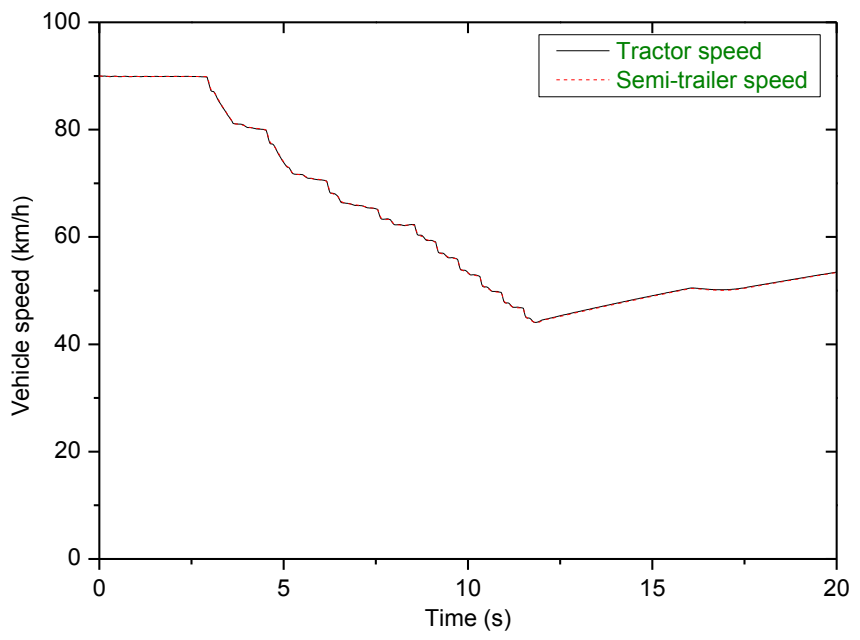

Fig. (10). Vehicle speeds with rollover prevention.

Fig. (10) shows the vehicle speeds decrease due to the differential braking with rollover prevention control activated.

With the rollover prevention control, the tractor semitrailer can travel on a road bend at a high speed even with an applied step input on the steering wheel, as shown in Fig. (11).

\section{CONCLUSION}

In general, as a transport vehicle, the tractor semitrailer is subject to wide variation in loading. The weight 
and distribution of the cargo load both influence the CG height of the truck. The factors affecting tractor semitrailer rollover usually include vehicle types, vehicle stiffness, vehicle speed, steering angle, vehicle payload, the CG of the payload, tires, suspensions, and roadway surfaces/tire adhesion coefficient.

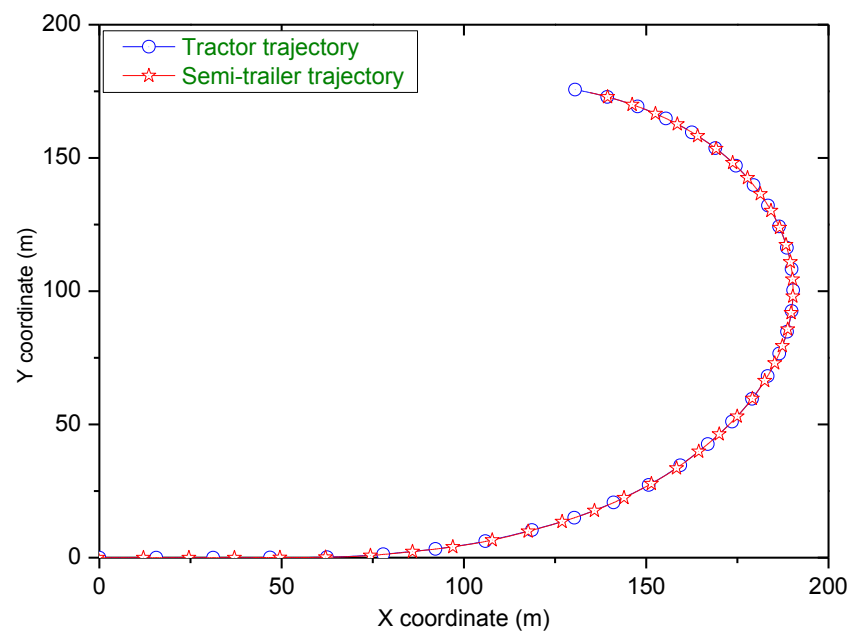

Fig. (11). Vehicle trajectory rollover prevention.

In this paper, a rollover prevention control method was proposed based on real-time calculation of rollover index. The vehicle CG height is estimated through one lateral acceleration sensor and suspension deflection sensors. Comparing the rollover index with the preset threshold, the differential braking will be applied to corresponding wheels once the trigger conditions are met. A roll stability control simulation was performed on the dynamic model based on virtual prototyping. The results show that the rollover prevention control proposed in this paper can stabilize the tractor semi-trailer and prevent from rolling over from driving on bends in high speed.

\section{CONFLICT OF INTEREST}

The authors confirm that this article content has no conflict of interest.

\section{ACKNOWLEDGEMENTS}

This work is partially supported by the National Natural Science Foundation of China (Grant No.51205051), the Fundamental Research Funds for the Central Universities (Grant No.N120403015), the Natural Science Foundation of Liaoning Province, China (Grant No.201202070) and the $\mathrm{PhD}$ Start-up Fund of Natural Science Foundation of Liaoning Province, China (Grant No. 20131096). Thanks for the help.

\section{REFERENCES}

[1] S. W. Zhou, and S.Q. Zhang, "Jackknife control on tractor semitrailer during high speed curve driving", Sensors \& Transducers, vol.16, pp. 277-84, 2012.

[2] S. W. Zhou, and S.Q. Zhang, "Assessing the effect of chassis torsional stiffness on tractor semi-trailer rollover", Applied Mathematics \& Information Sciences, vol. 7, pp. 633-637, 2013.

[3] S. Bennett, and I.A. Norman, Heavy Duty Truck Systems. New York: Delmar, Cengage Learning, 2011.

[4] D. Pape, Heavy Truck Rollover Characterization (Phase-A) Final Report. Knoxville: National Transportation Research Center, Inc., 2009.

[5] R. Marimuthu, B. Jang, and S. Hong, "A Study on SUV Parameters Sensitivity on Rollover Propensity", SAE Technical Paper 200601-0795.

[6] R. Rajamani, D. Piyabongkarn, V. Tsourapas, and J. Y. Lew, "Parameter and state estimation in vehicle roll dynamics", Intelligent Transportation Systems, IEEE Transactions on, vol. 12, pp. 1558-1567, 2011.

[7] J. H. Huang, and W. C. Lin, "EKF-Based In-vehicle estimation of relative CG Height", in ASME 2008 Dynamic Systems and Control Conference, 2008, pp. 103-110.

[8] C. Winkler, "Rollover of heavy commercial vehicles", UMTRI Research Review, vol. 31, pp. 1-20, 2000.

[9] Z. L. Wang, MATLAB/Simulink and Control System Simulation (2 ${ }^{\text {nd }}$ edition). Beijing: Publishing House of Electronics Industry, 2008. 